\title{
Anxiogenic-Like Action of Galanin after Intra-Amygdala Administration in the Rat
}

\author{
Christian Möller, M.D., Wolfgang Sommer, M.D., Ph.D., Annika Thorsell, M.Sc., \\ and Markus Heilig, M.D., Ph.D.
}

The neuropeptide galanin is expressed in brain structures implicated in regulation of emotionality. The amygdala is known to play a central role in mechanisms of fear and anxiety. We therefore examined the effects of galanin $(0.2$ and $0.6 \mathrm{nmol} /$ side) on experimental anxiety upon microinjection into the amygdala. Two established animal models of anxiety were used: a punished drinking test, and the elevated plus-maze. Punished responding was dose dependently suppressed by intra-amygdala galanin, whereas unpunished responding, drinking motivation, locomotor activity, and shock thresholds were unaffected. No effects on experimental anxiety were seen in the plusmaze following galanin injection. When injected into parietal cortex, no anxiety promoting properties of galanin were detected. These data suggest that activation of galanin receptors in amygdala modulates neurotransmission involved in fear and experimental anxiety.

[Neuropsychopharmocology 21:507-512, 1999]

(C) 1999 American College of Neuropsychopharmacology. Published by Elsevier Science Inc.
KEY WORDS: Galanin; Amygdala; Anxiety; Conflict, Plus-maze

Galanin, a 29 amino acid peptide (30 in humans) originally isolated from the porcine intestine in 1983 (Tatemoto et al. 1983), is widely distributed in the central nervous system of mammals, including both rat (Melander et al. 1986) and humans (Gentleman et al. 1989). There are specific membrane associated receptors to which galanin binds with an affinity in the nanomolar range, suggesting a role for this peptide as a neurotransmitter in vivo. Numerous studies have pointed out possible effects of galanin; a role for the peptide has been proposed in memory function (Ögren et al. 1992), food intake (Kyrkouli et al. 1990) and endocrine control (Bartfai et al. 1992). Galanin receptor agonists are

From the Department of Clinical Neuroscience and Family Medicine, Karolinska Institute, Stockholm, Sweden.

Address correspondence to: M. Heilig, M.D., Addiction Center South, Clinical Research Center, Novum, Huddinge University Hospital, 14186 Huddinge, Sweden.

Received May 28, 1998; revised October 2, 1998; accepted October 16, 1998. thought to relieve pain (Wiesenfeld-Hallin et al. 1990) and prevent ischaemic damage (Ari and Lazdunski, 1989), and galanin receptor antagonists are being tried in the treatment of depression (Seutin et al. 1989), feeding disorders, and Alzheimers disease (Chan-Palay, 1988).

Brain structures important for emotionality, such as the amygdala and the hypothalamus, show a rich expression of galanin and galanin receptors (Bartfai et al. 1993; Bartfai et al. 1992). A previous study (Bing et al. 1993) has implied a role for galanin in neural mechanisms underlying anxiety. In that study, galanin was administered intracerebroventricularly (ICV) and produced a modest release of punished responding, normally interpreted as a reduction of experimental anxiety, with a bell-shaped dose-response curve. The anatomical site through which this action is mediated has not been elucidated. Converging evidence points to the amygdala as a critical structure in the regulation of functions related to fear and anxiety (Davis 1992; Davis et al. 1994; Möller et al. 1997). In the present study, therefore, we examined the effects of intraamygdala administered galanin on levels of experimental anxiety. 
Two established and pharmacologically validated animal models of anxiety were used, a punished drinking test and the elevated plus-maze. Behavioral specificity was assessed by obtaining measures of unpunished drinking in the same apparatus where punished drinking was studied, drinking motivation under normal caging conditions, pain thresholds, and exploratory locomotor activity. As a control of the anatomical specificity, we also examined the effects of galanin on measures of experimental anxiety upon administration into parietal cortex.

\section{MATERIALS AND METHODS}

\section{Subjects}

Male Wistar rats (BK, Sollentuna, Sweden), weighing between 280 and $300 \mathrm{~g}$ at the start of the experiment were used. Animals were housed four per cage, except for 3 days postsurgery, when they were kept in individual cages. Lights were on at $0700 \mathrm{~h}$ and off at $1900 \mathrm{~h}$, and the temperature was $21-23^{\circ} \mathrm{C}$. Standard laboratory chow and tap water were available at all times, except during the conflict test (see below). Subjects were allowed at least 1 week of adaptation to the animal facility before any procedures. Before experiments, all animals were handled $3 \times 5$ min to minimize interference from procedural stress. All experimental procedures were approved by the local animal ethics committee.

\section{Over-all Design}

Amygdala-Implanted Subjects. To control for possible effects of repeated galanin administration on anxiety-related behaviors, conflict and plus-maze testing were carried out in two batches of amygdala-implanted subjects, in a counterbalanced design. One batch was first tested in the conflict paradigm, and, following a 1 -week recovery and random reassignment to new treatment groups, on the elevated plus-maze. In the second batch, conflict and plus-maze testing were carried out in reverse order. In addition, in the first batch of amygdala subjects, locomotor testing was carried out immediately following plus-maze testing, and, following an additional week of recovery and another random reassignment to treatment groups, shock thresholds were examined. In batch two, following a 1-week recovery and random reassignment to treatment groups, drinking motivation was studied.

Parietal Cortex-Implanted Subjects. These were studied in the conflict test as a negative specificity control group following the observation of proconflict actions of galanin after intra-amygdala administration. Because no actions of intra-amygdala galanin were observed in the plus-maze, the parietal cortex group was not examined in that paradigm.

\section{Surgery and Intracerebral Microinjections}

Under ketamin/xylazine anesthesia $(80 \mathrm{mg} / \mathrm{kg}$ resp 15 $\mathrm{mg} / \mathrm{kg}$ ), animals were stereotactically implanted with stainless steel guide cannulas (Plastics One, Roanoke, VA), which were secured to the skull using stainless steel screws and acrylic cement. Cannulas were closed at all times with obturators when not used. Tooth bar was at $3.3 \mathrm{~mm}$ below interaural line. For central amygdala, coordinates were: $2.3 \mathrm{~mm}$ posterior and 4.3 $\mathrm{mm}$ lateral to bregma, $8.3 \mathrm{~mm}$ ventral to skull surface; for parietal cortex: $2.3 \mathrm{~mm}$ posterior and $4.2 \mathrm{~mm}$ lateral to bregma, $4.3 \mathrm{~mm}$ ventral to skull surface (Paxinos and Watson 1986). At least 10 days of recovery were allowed after surgery before continued experiments.

For injections, a 28-gauge injector connected to a 1.0 $\mu l$ Hamilton syringe with plastic tubing was used. Injections (saline, or porcine galanin, Diagnostika, Falkenberg, Sweden), were given $15 \mathrm{~min}$ before testing over 3 min, in a vol of $0.5 \mu \mathrm{l} /$ side, followed by a $1 \mathrm{~min}$ latency before withdrawing the cannulas. The pretreatment interval was chosen based on our previous experience with intra-amygdala neuropeptide injections (Heilig et al. 1993) and previous reports from other laboratories indicating that feeding effects of galanin persist for up to $1 \mathrm{~h}$ following injection (Kyrkouli et al. 1990). For verification of correct placement of injections, brains were removed following the completion of experiments, cryostat sections at the level of injection were obtained, and injection sites were histologically verified.

\section{Punished Drinking Test}

A modified Vogel's punished drinking/conflict test was used (Vogel et al. 1971). Training and testing of animals was performed in sound-attenuated operant chambers (Med. Associates, St. Albans, VT) equipped with a grid floor of stainless steel bars and a drinking bottle containing $5 \%(\mathrm{w} / \mathrm{v})$ glucose solution. Following $24 \mathrm{~h}$ of water deprivation, animals were habituated for $12 \mathrm{~min}$ to the chamber. After an additional $24 \mathrm{~h}$ period of water deprivation, animals were adapted once more to the same test chamber for a further $12 \mathrm{~min}$, during which free access was given to the glucose solution. Finally, after a further $24 \mathrm{~h}$ period of water deprivation, animals were returned to the operant chamber for the testing session.

Behavioral testing was under the control of a computerized system (Med Associates, St. Albans, VT). Contact with the drinking spout was detected electronically. To establish drinking behavior, subjects were allowed three drinking episodes before the timer started. 
This was followed by a 4-min unpunished drinking component, during which drinking episodes were detected, but no shock was administered. Finally, an 8-min punished drinking, conflict component followed, during which electric shock $(0.20 \mathrm{~mA}$ over $2 \mathrm{~s})$ was delivered upon every drinking episode, and the number of punished drinking episodes was recorded. Under these conditions, we and others have found established anti-anxiety compounds, such as diazepam, to produce a marked release of punished drinking (data not shown).

\section{Elevated Plus-Maze}

Plus-maze testing was essentially as originally described (Pellow et al. 1985; Pellow and File, 1986). The apparatus was made of black plastic with a rubber floor and consisted of two open arms measuring $50 \times 10 \mathrm{~cm}$ and two arms of the same size surrounded by $40-\mathrm{cm}$ high end and side walls. The arms were connected by a central area measuring $10 \times 10 \mathrm{~cm}$, and the maze was $50 \mathrm{~cm}$ above the floor during testing, which was undertaken under dim red light. Behavior was scored by a trained observer unaware of treatment conditions. Subjects were placed in a novel environment, an empty operant chamber, for $5 \mathrm{~min}$ prior to testing; this has been shown to increase exploratory activity and improve the reliability of subsequent plus-maze testing (Pellow et al. 1985). At the beginning of a session, the rat was placed in the central area of the maze, facing one of the open arms. The number of entries made into open and closed arms and the time spent in open and closed arms were recorded over a 5-min session. An arm entry was defined as all four paws into an arm.

\section{Locomotor Activity}

Exploratory locomotor activity was determined immediately after plus-maze testing. Subjects were placed in locomotor activity cages equipped with infrared beam detection (Med. Associates, St. Albans, VT). Interbeam distance was $8.5 \mathrm{~cm}$ horizontally and $6.5 \mathrm{~cm}$ vertically, and activity was recorded for $30 \mathrm{~min}$ at intervals of $10 \mathrm{~min}$.

\section{Shock Thresholds}

Shock thresholds were determined stepwise by manually increasing the current delivered as a scrambled pulse through the grid floor $(0.09,0.12,0.15,0.18,0.21$, $0.24 \mathrm{~mA}$ ) until the rat showed a reaction to the electrical stimulus (jump, jerk, or similar) as judged by an observer blind to the treatment and the shock level applied. Between each step, there was at least a 15-s shockfree interval.

\section{Drinking Motivation Test}

Subjects were water deprived for $24 \mathrm{~h}$ in the home cage. Following intra-amygdala injections, subjects were placed in individual cages. Fifteen min postinjection, each cage was supplied with a preweighed 50-ml drinking bottle, and the amount of liquid consumed over 15 min was recorded.

\section{Statistical Analysis}

Amygdala Subjects. In the punished drinking model, two-way analysis of variance (ANOVA) with respect to treatment and test session was separately performed for unpunished and punished drinking, respectively. Tukey's post hoc test was performed to evaluate individual group comparisons. In the plus-maze, two-way ANOVAs with respect to treatment and test session were separately performed for the percentage time spent on, and the percentage entries made into the open arms. The same procedure was carried out for the total number of entries (open + closed arms). For locomotor activity, a factorial ANOVA for treatment, time, and treatment $\times$ time was performed. Water consumption in the drinking motivation test was compared using a one-way ANOVA. Shock thresholds, which do not fulfill assumptions of normal distribution and homogeneity of variance, were compared using Mann-Whitneys U-test.

Parietal Cortex Subjects. One-way ANOVA was separately performed for unpunished and punished drinking, respectively.

\section{RESULTS}

\section{Conflict Test}

Unpunished drinking was unaffected by intra-amygdala galanin $(\mathrm{F}[2,40]=1.7, p=.20)$. Saline-injected controls $(0.5 \mu \mathrm{l} /$ side) showed an average of $49.8 \pm 8.2$ (mean \pm SEM) unpunished drinking episodes; whereas, galanin ( 0.2 or $0.6 \mathrm{nmol}$ in $0.5 \mu \mathrm{l}$ saline/side) showed an average of $41.7 \pm 5.4$ and $35.0 \pm 4.7$ unpunished drinking episodes, respectively. In contrast, punished drinking was suppressed by galanin treatment in a highly significant and dose-dependent manner (treatment effect; $\mathrm{F}[2,40]=6.0, p=.005$; Tukey's post hoc test $-0.2 \mathrm{nmol}$ vs. saline: $p=.04 ; 0.6 \mathrm{nmol}$ galanin vs. saline: $p=.005$ ). The numbers of punished drinking episodes were $100.8 \pm$ 15.7, $60.9 \pm 10.7$ and $48.9 \pm 12.0$ for controls, $0.2 \mathrm{nmol}$ and $0.6 \mathrm{nmol}$ galanin, respectively (see Figure 1). The effect of galanin on punished drinking did not differ between the two sessions, as witnessed by a nonsignificant session $\times$ treatment interaction in the ANOVA $(\mathrm{F}[2,40]=0.24, p=.79)$. 


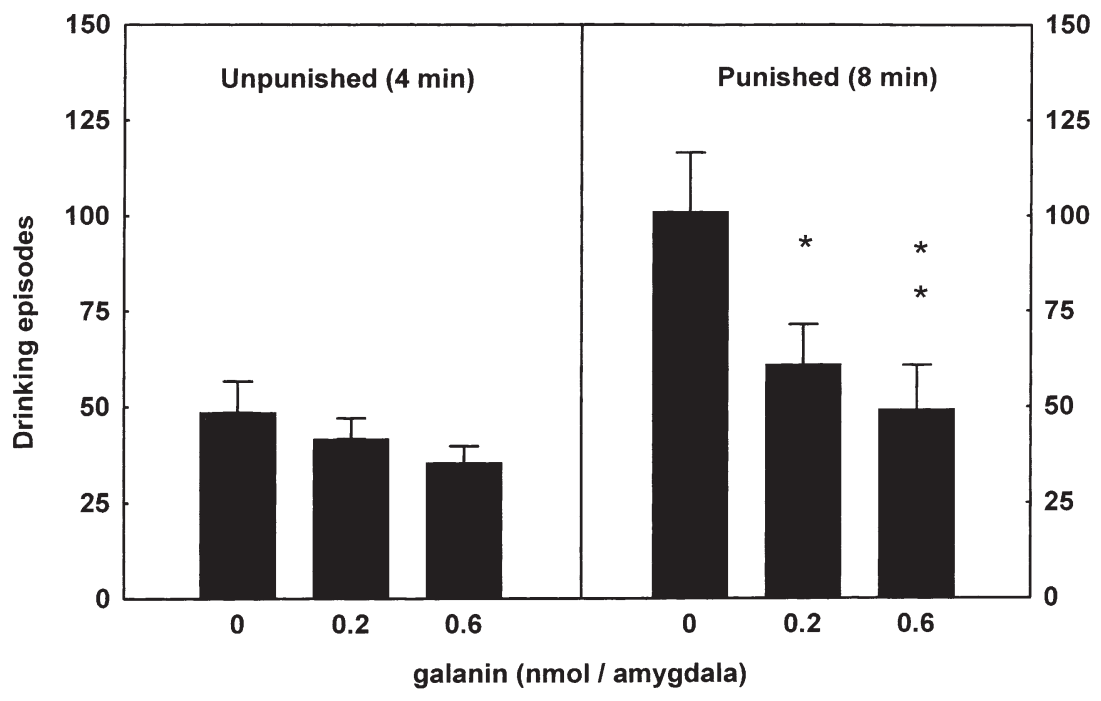

Figure 1. Unaffected unpunished drinking, and dose-dependent decrease in punished drinking in galanin-injected animals (* and ** indicate $p<.05$ or .01 respectively; for detailed statistics, see Results section). Number of drinking episodes is shown (mean \pm SEM, $n=15$ for controls and high galanin, $n=16$ for low galanin) during a 4-min unpunished and an 8-min conflict component, during which each drinking episode resulted in a 2-s, 0.20-mA shock between the drinking spout and the grid floor.

\section{Shock Thresholds}

This parameter was not affected by the higher of the galanin doses found effective in the conflict test, 0.6 nmol galanin/amygdala $(0.196 \pm 0.009 \mathrm{~mA}$ vs $0.194 \pm$ $0.006 \mathrm{~mA}$, Mann-Whitney U-test; $p=.81$, ns, for controls and $0.6 \mathrm{nmol}$ galanin/side injected animals, respectively), indicating that results observed in the conflict test were not attributable to effects of galanin on nociception.

\section{Drinking Motivation Test}

Drinking motivation was also unaffected by the 0.6 $\mathrm{nmol} /$ amygdala galanin dose $(11.4 \pm 0.9 \mathrm{ml} / 15 \mathrm{~min}$ vs. $13.2 \pm 1.1 \mathrm{ml} / 15 \mathrm{~min} ; \mathrm{F}[1,14]=1.7 ; p=.20$ for controls and galanin injected subjects, respectively), indicating that results observed in the conflict test were not attributable to effects of galanin on thirst.

\section{Anatomical Specificity of the Proconflict Effect}

To examine the anatomical specificity of the proconflict effects obtained with intra-amygdala administration of galanin, we also examined the effects of galanin administered into parietal cortex on measures of experimental anxiety in the punished drinking test. No difference between groups could be detected (unpunished drinking episodes $44.2 \pm 4.2$ vs. $45.8 \pm 4.0, \mathrm{~F}(1,22)=0.07, p=.79$; punished drinking episodes $32.6 \pm 4.6$ vs. $25.8 \pm 4.3$, $\mathrm{F}[1,22]=1.16, p=.29$, ns, for controls and galanininjected animals $(0.6 \mathrm{nmol} /$ side $)$, respectively).

\section{Elevated Plus-Maze}

In this model, no difference was detected between controls and animals receiving galanin $(0.6 \mathrm{nmol} / \mathrm{side})$. Both parameters related to experimental anxiety, percentage time spent on open arms, and percentage entries made into open arms, were unaffected $(\mathrm{F}[1,48]=$ $0.15, p=.70$, resp $\mathrm{F}[1,48]=0.60, p=.44, \mathrm{~ns})$. Activity during plus-maze testing, as reflected in the total number of entries made during the 5 -min session on the plus-maze, was also unaffected $(\mathrm{F}[1,48]=0.001, p=.97$; Table 1.)

\section{Locomotor Activity}

In agreement with the result obtained during plusmaze testing, saline-injected controls and galanininjected animals $(0.6 \mathrm{nmol} /$ side) showed similar levels of activity in the locomotor testing $(\mathrm{F}[2,48]=1.29, p=$

Table 1. Unaffected Measures of Experimental Anxiety and Over-all Activity in the Elevated Plus-Maze Following Injection of Saline or $0.6 \mathrm{nmol}$ Galanin/Amygdala (mean \pm SEM; $n=22$ and 28 , resp).

\begin{tabular}{lccc}
\hline & Control & Galanin & \\
\hline Time (\% open/open + closed) & $44.4 \pm 5.5$ & $48.0 \pm 4.2$ & $p=.70, \mathrm{~ns}$ \\
Entries (\% open/open + closed) & $49.3 \pm 4.1$ & $46.5 \pm 2.8$ & $p=.44, \mathrm{~ns}$ \\
Total entries & $14.6 \pm 1.1$ & $15.0 \pm 1.1$ & $p=.97, \mathrm{~ns}$ \\
\hline
\end{tabular}


$.29 ; \mathrm{F}[2,48]=0.66, p=.52$ for horizontal and vertical activity, respectively; Figure 2).

\section{DISCUSSION}

In this study, galanin dose-dependently suppressed punished drinking in an established animal model of anxiety, the punished drinking test. Unpunished drinking was unaffected by this treatment. Also, in an independent drinking motivation test, drinking was not affected by intra-amygdala galanin at the higher of the doses that suppressed conflict behavior. Intra-amygdala galanin has previously been shown to stimulate feeding, but to leave drinking unaffected (Kyrkouli et al. 1990; Corwin et al. 1993). Our results are in agreement with these findings. Therefore, it does seem unlikely that the proconflict/anxiogenic-like effect observed in the present study was attributable to a suppression of thirst or other appetitive motivation by galanin.

Furthermore, although antinociceptive effects of central galanin have been reported after intrathecal administration (Wiesenfeld-Hallin et al. 1990), it is unlikely that the suppression of punished drinking observed in the present study was related to this type of galanin action, because shock thresholds were unaffected by intra-amygdala galanin treatment. Moreover, no effects of intra-amygdala galanin were seen on locomotor activity, or over-all activity on the plus-maze. Therefore, it also seems unlikely that the suppression of punished drinking seen with intra-amygdala galanin was attributable to adverse motor performance effects of the peptide. Finally, the proconflict effect of galanin was not reproduced by injections into the parietal cortex. In our interpretation, the present data suggest that activation of galanin receptors within the amygdala increases experimental anxiety in a behaviorally and anatomically specific manner.

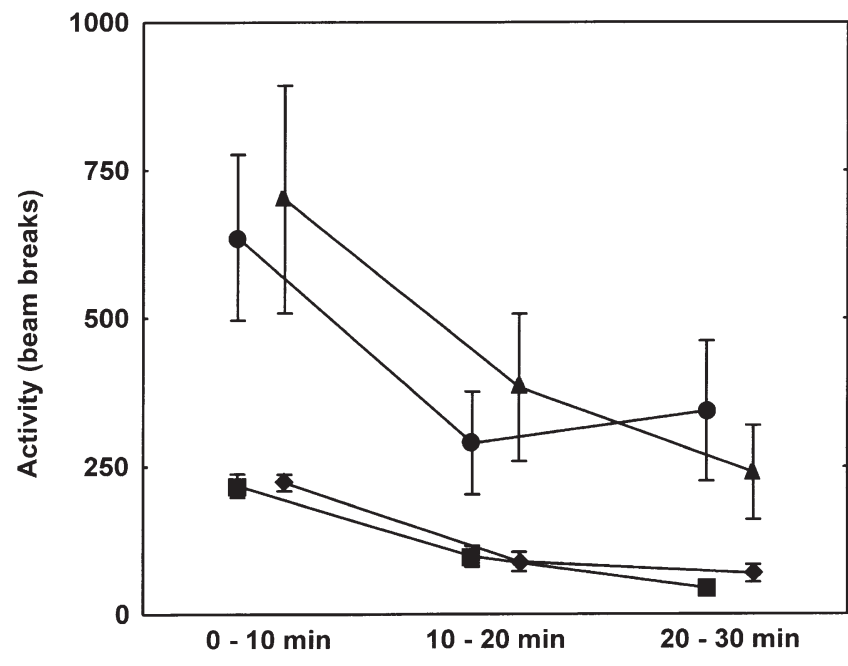

The role of the amygdala, and especially its central nucleus, in mechanisms of fear and anxiety has been supported in numerous studies (Davis 1992; Kopchia et al. 1992; Davis et al. 1994; Möller et al. 1997). Using ibotenic acid lesions, we recently demonstrated that cell bodies located in central amygdala are critically involved in the regulation of conflict behavior (Möller et al. 1997). The neurochemical nature of cell bodies involved in this regulation has not been established. Galanin binding has been observed within the central nucleus (Dutriez et al. 1996), and this structure contains the cell bodies of numerous output neurons of the amygdala complex (see Davis et al. 1994). Activation of galanin receptors under conditions of conflict may, thus, modulate the functional output of the amygdala complex to its effector targets.

The present results contrast with a previous report, in which intracerebroventricular administration of galanin produced a modest anxiolytic-like/anticonflict effect, with an inverted-U-shaped dose response curve (Bing et al. 1993). The anatomical localization through which that action of galanin was mediated is not known. It is, therefore, possible that intraventricular treatment affects galanin receptors unrelated to the amygdala complex. Alternatively, pre- and postsynaptic galanin receptors may be differentially activated with the two modes of administration, accounting for the differential effects observed.

In the elevated plus-maze, no effect of intraamygdala administered galanin was found. It has been suggested that the plus-maze may reflect particular aspects of anxiety, which differ from those gauged by other animal models (Handley and McBlane 1993). Recently, however, we found evidence that differences observed between the elevated plus-maze and a conflict procedure are likely to be related to the markedly lower stress level of the former and that cell bodies located within central amygdala may contribute to the regula-

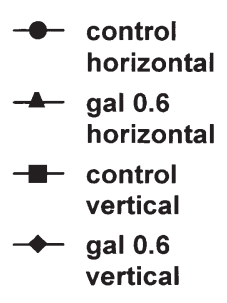

Figure 2. Unaffected locomotor activity after administration of $0.6 \mathrm{nmol}$ galanin/ side $45 \mathrm{~min}$ before testing versus control animals; $n=13$ for both groups. See Results section for detailed statistics. 
tion of experimental anxiety only when activated by a stressor (Möller et al. 1997). Against this background, we note that activation of galanin receptors within the amygdala seems to have little intrinsic effect under the low-activation state of plus-maze testing, but seems to potently potentiate ongoing anxiogenic signaling under the markedly stressful condition of conflict testing.

Actions of galanin in other systems, such as learning and memory effects mediated through the hippocampus-septum pathway, have been shown to be related to galanin modulation of cholinergic transmission (Crawley 1996). Our present results suggest a similar, modulatory rather than direct mode of galanin action with respect to fear-related behaviors. The molecular nature of transmission modulated by galanin remains to be established.

In summary, we conclude that activation of galanin receptors within the amygdala seems to dose-dependently potentiate neuronal signaling mediating fearrelated behavior. Such a modulatory mode of action may prove advantageous if antagonism of galanin receptors is explored as a therapeutic principle in the treatment of pathological fear. If it becomes feasible to target amygdala galanin receptors selectively, such a strategy may offer the prospect of blocking fear-related signaling without interfering with normal neuronal activity.

\section{REFERENCES}

Ari YB, Lazdunski M (1989): Galanin protects hippocampal neurons from the functional effects of anoxia. Eur J Pharmacol 165:331-332.

Bartfai T, Fisone G, Langel U (1992): Galanin and galanin antagonists: Molecular and biochemical perspectives. Trends Pharmacolog Sci 13:312-317

Bartfai T, Hokfelt T, Langel U (1993): Galanin-A neuroendocrine peptide. Crit Rev Neurobiol 7:229-274

Bing O, Möller C, Engel JA, Söderpalm B, Heilig M (1993): Anxiolytic-like action of centrally administered galanin. Neurosci Lett 164:17-20

Chan-Palay V (1988): Galanin hyperinnervates surviving neurons of the human basal nucleus of Meynert in dementias of Alzheimer's and Parkinson's disease: A hypothesis for the role of galanin in accentuating cholinergic dysfunction in dementia. J Comp Neurol 273: 543-557

Corwin RL, Robinson JK, Crawley JN (1993): Galanin antagonists block galanin-induced feeding in the hypothalamus and amygdala of the rat. Eur J Neurosci 5:1528-1533

Crawley JN (1996): Minireview: Galanin-acetylcholine interactions: Relevance to memory and Alzheimer's disease. Life Sci 58:2185-2199

Davis M (1992): The role of the amygdala in fear and anxiety. Ann Rev Neurosci 15:353-375

Davis M, Rainnie D, Cassell M (1994): Neurotransmission in the rat amygdala related to fear and anxiety. Trends Neurosci 17:208-214

Dutriez I, Lagny-Pourmir I, Epelbaum J, Beauvillain JC (1996): Autoradiographic quantitation and anatomical mapping of GTP-sensitive galanin receptors in the guinea pig central nervous system. J Chem Neuroanat 12:85-104

Gentleman SM, Falkai P, Bogerts B, Herrero MT, Polak JM, Roberts GW (1989): Distribution of galanin-like immunoreactivity in the human brain. Brain Res 505:311-315

Handley SL, McBlane JW (1993): An assessment of the elevated X-maze for studying anxiety and anxiety-modulating drugs. J Pharmacolog Toxicolog Meth 29:129-138

Heilig M, McLeod S, Brot M, Heinrichs SC, Menzaghi F, Koob GF, Britton KT (1993): Anxiolytic-like action of neuropeptide Y: Medication by Y1 receptors in amygdala and dissociation from food intake effects. Neuropsychopharmacology 8:357-363

Kopchia KL, Altman HJ, Commissaris RL (1992): Effects of lesions of the central nucleus of the amygdala on anxiety-like behaviors in the rat. Pharmacol Biochem Behav 43:453-461

Kyrkouli SE, Stanley BG, Seirafi RD, Leibowitz SF (1990): Stimulation of feeding by galanin: Anatomical localization and behavioral specificity of this peptide's effects in the brain. Peptides 11:995-1001

Melander T, Hokfelt T, Rokaeus A (1986): Distribution of galanin-like immunoreactivity in the rat central nervous system. J Comp Neurol 248:475-517

Möller C, Wiklund L, Sommer W, Thorsell A, Heilig M (1997): Decreased experimental anxiety and voluntary ethanol consumption in rats following central but not basolateral amygdala lesions. Brain Research 760:94-101

Paxinos G, Watson C (1986): The Rat Brain in Stereotaxic Coordinates, 2nd ed. San Diego, Academic Press

Pellow S, Chopin P, File SE, Briley M (1985): Validation of open-closed arm entries in an elevated plus-maze as a measure of anxiety in the rat. J Neurosci Meth 14:149167

Pellow S, File SE (1986): Anxiolytic and anxiogenic drug effects on exploratory activity in an elevated plus-maze: A novel test of anxiety in the rat. Pharmacol Biochem Behav 24:525-529

Seutin V, Verbanck P, Massotte L, Dresse A (1989): Galanin decreases the activity of locus coeruleus neurons in vitro. Eur J Pharmacol 19:373-376

Tatemoto K, Rokaeus A, Jornvall H, McDonald TJ, Mutt V (1983): Galanin-A novel, biologically active peptide from porcine intestine. Febs Lett 164:124-128

Vogel JR, Beer B, Clody DE (1971): A simple and reliable conflict procedure for testing anti-anxiety agents. Psychopharmacologia 21:1-7

Wiesenfeld-Hallin Z, Xu XJ, Villar MJ, Hökfelt T (1990): Intrathecal galanin potentiates the spinal analgesic effect of morphine: Electrophysiological and behavioral studies. Neurosci Lett 109:217-221

Ögren SO, Hökfelt T, Kask K, Langel U, Bartfai T (1992): Evidence for a role of the neuropeptide galanin in spatial learning. Neuroscience 51:1-5 